10-1991

The Commons: A Multidisciplinary Approach to Nonprofit Organization, Voluntary Action and Philanthropy

Roger A. Lohmann

Follow this and additional works at: https://researchrepository.wvu.edu/faculty_publications

Part of the Nonprofit Administration and Management Commons, Political Science Commons, Public Affairs, Public Policy and Public Administration Commons, Social Work Commons, Sociology Commons, Sports Studies Commons, and the Urban Studies and Planning Commons 


\title{
The Commons: A Multidisciplinary Approach to Nonprofit Organization, Voluntary Action and Philanthropy ${ }^{1}$
}

\author{
Roger A. Lohmann, Ph.D. \\ West Virginia University
}

\begin{abstract}
The task of identifying nonprofit organizations, voluntary action and philanthropy as the principal constituents of a single "sector" within the larger economy, society and polity has been a central challenge for the multidisciplinary paradigm which seems to be emerging in this field. The concepts of the commons and common goods are presented as concepts with important multi-disciplinary implications. The commons is characterized by uncoerced participation, shared purposes and resources, mutuality and fairness and the derivative concept of common goods, as desirable ends which are universal and indivisible within a commons but not necessarily beyond. Taken together, commons and common goods offer the basis for a shared paradigm which can resolve the sector problem.
\end{abstract}

\section{Introduction: In Search of A Common Paradigm}

A primary task of any science is to identify the phenomena it seeks to describe and explain, and define them in terms which facilitate investigation and application. With respect to the current agenda of scientific interests of nonprofit, voluntary and philanthropic researchers, significant portions of this basic scientific yeomanry took place long ago within several separate academic disciplines and scientific fields. Voluntary organizations in sociology, charity (and later community) organization in social work, nonprofit organization in public administration and cooperative extension as well as fund accounting and trust law were until quite recently minuscule sub-specialties within existing disciplinary frameworks and in no position to compete with or challenge entrenched disciplinary paradigms. Other nonprofit and voluntary action topics such as managing volunteers and fund raising appear to have emerged entirely outside the organized knowledge industry of the universities, with its order of disciplines and sciences.

Since the origins of the Association for Voluntary Action Scholars (AVAS) in the early 1970's, different groups of specialists have been discovering and building upon mutual, overlapping and at times competing interests under various different ad hoc umbrellas. Recently, there have been a profusion of new programs, institutes,

\footnotetext{
${ }^{1}$ A revised and edited version of this manuscript was published as Lohmann, R. A. (1992). The Commons: A Multidisciplinary Approach to Nonprofit Organizations, Voluntary Action and Philanthropy. Nonprofit and Voluntary Sector Quarterly, 21(3), 309-324. doi:10.1177/089976409202100308.
} 
associations, sciences, curricula and even professions proclaimed in voluntary and nonprofit studies. In fact, it appears that nonprofit and voluntary studies are currently undergoing one of those unpredictable, but recognizable, crises of opportunity which occasionally come along to shake up the established order of things.

One of the clearest indicators of something happening is the number of book publishers currently out trolling for manuscripts in this field. Publishers representatives are seldom found among the crusaders for lost causes and moribund interests. Suddenly many are not only willing but downright eager to expand their lists in this area. As a result, the published work in this area is growing dramatically. Where once anyone with interests in this area could reasonably expect to rather easily keep abreast of everything published in a particular specialized interest in this field, this is becoming increasingly more difficult with each passing year.

The sudden upsurge of interest in "the sector" has exposed the apparent lack of a general theoretical framework -- a general paradigm, if you will -- to encompass the entire subject and to relate specific interests and topics to one another. Smith and Freedman concluded more than two decades ago that "the term theory has to be applied to the study of voluntary associations with care, since very little theory, in any strict sense of the word, has yet been developed in the field. There is no grand, all encompassing, and generally accepted theory of voluntarism, or even a respectable middle range theory." $(1970,1)$ Several of the authors writing in the 1987 collection of research on nonprofit organizations make exactly the same point. (See ) Regrettably, this assessment is still accurate today, although the number of provocative and insightful premises, definitions and propositions is considerably larger than it was two decades ago.

While Tocqueville provides a natural and durable starting point, and offers great depth of insight on the nature of democratic society, his comments about "the sector" are rather sparse and by now somewhat threadbare. In sociology, David Horton Smith has done much to articulate the nature of the "voluntary sector", while Smith and Freedman's review of the voluntary literature remains interesting and useful. (Smith, 1972; Smith and Freedman, 1972) In social work, Ralph Kramer has led a small cadre of those interested in voluntary agencies in recent years. (Kramer, 1982). Burton Weisbrod (1988) has summarized and synthesized the remarkable distillation of a bone fide nonprofit economics which seems to have taken place in less than a decade. A great many more individual and collective contributions worthy of note could be identified in each of the topic and interest areas of contemporary nonprofit and voluntary action studies.

Yet none of these disciplinary approaches appears to offer core concepts or theory capable of sustaining a genuinely coherent interdisciplinary view of what remains a vast collection of vaguely related topics and issues. What is still needed is a general paradigm or theoretical model to unify and bring some conceptual order to the whole. Several years ago, Van Til proposed the French "social economy" 
approach as a possible paradigm. (Van Til, 1988) Others have identified facets of the relative advantages of the nonprofit sector in comparisons with commercial/market and public/governmental sectors. (Hansmann, 1987)

The interdisciplinary nature of recent scholarly work on the third sector has disturbed and seriously eroded established patterns of disciplinary consensus over "the nature of the nonprofit beast" without offering any genuinely new overviews. The phenomenon brings to mind the repeated disturbances of normal science which are said to precede a paradigm shift in the Kuhnian model of scientific revolutions. (Bernstein, 1983, 68-70) The organization of an international and interdisciplinary community of practitioners, researchers and scholars began with the formation of AVAS and continues through the formation of the International Research Society for Voluntary Associations, Nonprofit Organizations and Philanthropy in March, 1991. Creation of a multidisciplinary research community has loosened disciplinary shackles which formerly constrained interests, narrowed possibilities for recognition and support, and limited opportunities for publication and community even as nonprofit and voluntary action studies have also become a genuinely international interest.

This is no longer a parochial Anglo-American topic. We are witnessing an extraordinary international outburst of creativity and energy in all areas of the study of nonprofit organizations, voluntary associations, philanthropy, volunteering, fund raising and all related topics. As a result, we have a stronger and more vibrant base of information and empirical data than has ever previously existed. Yet the sheer creativity of the moment is further exacerbating the question of a central paradigm.

Behind all of the enthusiasm, there is a certain malaise associated with our collective inability to resolve the central paradigm question. Unquestionably, there have been a large number of bold hypotheses and typologies put forward in recent years. Virtually every issue of the journals and every research conference are bristling with interesting new data and provocative new hypotheses. However, mountains of statistics and separate, uncoordinated hypotheses do not add up to sound theory. While typologies, like the NTEE classification scheme have important uses, typologies alone cannot settle underlying theoretical questions. (NTEE, 1988)

The emergent national and international interdisciplinary community of nonprofit and voluntary action scholars has yet to find its vital center. This is why so much recent work presented at meetings and conferences has been aimed at "relocating the core" of the field. Yet the problem remains, and grows more perplexing. The problem is not that we don't have a paradigm of nonprofit, voluntary and philanthropic studies. It is that we have too many. Each of the disciplines and professions with an historical interest in nonprofit and voluntary studies seeks to press to the center its own legacy of key concepts, problems, and methods of research or intervention. Yet none of these disciplinary and professional paradigms speaks to the full range of interests and concerns of the field. In addition, they don't articulate or "interface" particularly well, representing as they 
do most of the major social science controversies of the past three centuries. Is a nonprofit organization different from a voluntary association? Do religious organizations, political parties and fraternal orders produce public goods? Aren't the individualistic motivational paradigms of fund raising and volunteer management clearly at odds with both the utilitarian individualism of nonprofit economics and the social structuralism of nonprofit organizations?

The absence of a solid theoretical core for nonprofit, voluntary and philanthropic studies leaves us all uncertain as to when differences reflect significant variations in meaning and intent and when they reflect simple disciplinary or theoretical colloquialisms. Until we find a conceptual center, we can all expect to continue being inundated with various competing models and conceptions of all manner of sectors. Like other proposals before it, the ideas presented below will either contribute further to the clutter or add bristles to the broom needed to tidy up the mess!

Missing from the present situation is a set of central terms and concepts which embrace the diverse conceptions noted above and place specific issues and questions within a larger reference schema. In order to avoid as many as possible of the contentious disciplinary questions, it may be desirable to employ some new terminology not overloaded with narrow disciplinary connotations. However, at the same time, it appears desirable to avoid the terminological excesses often associated with the social sciences.

In this paper, I will concentrate on two conventional English language terms of long-standing duration: the commons is presented as an organizational/ structural term for naming "the sector" and common goods is offered as an associated evaluative term for labeling the goals, objectives, purposes, outputs, outcomes, products, and results of the sector. Together, these two terms form the conceptual core of an emerging theory of the commons which relocates and identifies the central (or common) interdisciplinary core of nonprofit organizations, voluntary action and philanthropy studies and distinguish it from the study of markets, states and households.

What results from adoption of these terms is an important shift in focus and perspective. Rather than assuming a paradigmatic role as the sine quo non of nonprofit, voluntary and philanthropic action, large, revenue-driven, professionally staffed nonprofit organizations, along with displays of oligarchic leadership and entrepreneurial behavior by their management might better be seen as elements of a larger continuum of theoretical possibilities of civil society ranging from pure altruism through total self-interest. The same applies equally well to the "true" volunteer and the "civic minded" foundation. Before such points can be explored more fully, however, it is necessary to clarify the central terms of the commons paradigm. 


\section{Overlapping Conceptions or Different Sectors?}

A major intersection of mutual interests in nonprofit, voluntary and philanthropic research and practice is probably to be found in the vicinity of that confusing group of sector terms which continue to attract so much attention. At present, no one may be completely sure whether a "nonprofit sector" is the same thing or something quite different from "voluntary" or "independent" or "nongovernmental" sectors. It is not even altogether clear whether references to "not-for-profit" whatevers are intended to apply to "nonprofits" as well. As such, the arena of sector talk offers a target of opportunity for zeroing in on the paradigm problem in nonprofit and voluntary studies: What exactly is it that represents the irreducible core of our mutual interests?

It may be possible and even desirable to introduce a higher level of interdisciplinary consensus by beginning with the recognition that each of these sector terms conveys both important nuances of different meaning and a core of common understandings. The most frequently used sector terms seem to be nonprofit, "not-for-profit", voluntary, nongovernmental, independent, philanthropic, third -- and reaching a bit -- eleemosynary. Each of these terms point to important phenomena and make critical distinctions. However, it is also clear by now that while each of them has its corps of followers, none has proven to denote the core around which the field as a whole has rallied. The key question, however, is whether any of these terms and their referents point to central, shared phenomena of concern throughout the field.

A nonprofit sector is usefully defined, following Hansmann's insightful distinction, as an economic network of corporations characterized by "nondistribution constraints"; legal and/or ethical restrictions on the distribution of any operating surpluses incidental to the corporation's activities (i.e. "profits") to shareholders, stockholders or stakeholders. (Hansmann, 1987) The concept has proven to be of greatest interest in economic, legal and management studies (some of whom insist on the alternate term "not-for-profit"). Once nonprofit is defined as Hansmann does, rather than by the theoretically threadbare notion of a "profit motive", the question raised by the growing popularity of "not-for-profit" as a substitute term is answered and the alleged distinction between the two terms becomes meaningless. If one accepts the central significance of the non-distribution constraint, "not-for-profit" is merely a slightly convoluted way of saying "nonprofit."

Regardless of preferred terms, the issue is not so much whether or not such a sector of corporations bound by the non-distribution constraint exists. Surely it does. The critical issue is whether corporations legally bound by the nondistribution constraint exhaust the limits of our mutual interests. Just as surely, they do not. However, the entire topic of social organizations bounded by ethnical rather than legal non-distribution constraints has yet to attract the attention it deserves. (We will return below to the question of whether a nonprofit corporation is the same as a nonprofit organization, as current usage seems to imply.) 
Similar close examination of other principal sector terms is equally revealing. Voluntarism is most typically used to connote lack of coercion or restraint in participation. Thus, the voluntary sector can be defined as a system of clubs, associations or groups characterized largely or exclusively by noncoercive membership and/or free and unconstrained participation. As such, the concept has been of empirical interest to sociologists, normative interest to democratic political theorists and practical interest to social workers, among others. (See Smith and Freedman, 1972 for a dated but still interesting review.)

Again, there is little doubt that such a voluntary sector exists in American, British, German and other European societies. (Bauer, 1990) But how does such a voluntary sector relate theoretically to a nonprofit sector? Even as we accept that a nonprofit sector is equivalent to a not-for-profit sector, can we accept further that a sector of constrained corporations is identical to a sector of noncoercive and unconstrained clubs, associations and groups? We can in the special case where the latter are all legally incorporated nonprofits bound by the non-distribution constraint. These two sector conceptions might also be equated if we are prepared to assume that an ethical non-distribution constrain is the equivalent of a legal one, and that voluntary clubs, associations and groups were uniformly bound by such ethical constraints. This seems unlikely. Thus we are left with two partially overlapping conceptions.

Looking in another direction, a nongovernmental sector can be defined as a network of organizations or institutions outside the formal apparatus of the political state and functioning independently of state oversight or direction, albeit capable of interacting with the state. This has proven a useful distinction for public administrators accustomed to distinguishing NGO's (nongovernmental organizations) from various public entities. From such a vantage point, the modern welfare state in the United States and elsewhere routinely incorporates such a nongovernmental sector. (Kramer, 1981) In fact, the term may be most commonly utilized in international social welfare discussions. The critical issue in defining NGO's appears to be neither distribution constraints nor participation.

The closely related notion of a third sector (O'Neill, 1988) is usually arrived at by the distinction between commercial-market and public-governmental (first and second) sectors and nonprofit NGO's (which are, presumably also nonmarket organizations, or NMO's). The third sector in this sense is simply the non-business (or non-market), side of civil society outside the family. Viewed thus, the third sector may be the last, or the third of four (the family or household sector) or even of five (what Smith (1991) calls the "informal" sector). (The theory of the commons concurs with Smith that retaining the membership sector is essential to a complete picture of nonprofit, voluntary and philanthropic action.)

The market-state-nonprofit sector distinction arises from Hobbes, through John Locke, John Stuart Mill and the general heritage of utilitarian social and political theory. In light of previous distinctions, it raises interesting issues of the degree to which nongovernmental and noncommercial organizations are also noncoercive and 
unconstrained. Perhaps the greatest weakness of the NGO concept is that it appears to be a content-empty negation. (For comments on the accumulation and utility of negative terms in nonprofit and voluntary action terminology, see Lohmann, 1989).

An independent sector would presumably be one able to function autonomously without untoward external interference or involvement. (Cornuelle, 1965; Independent Sector, 1988) Whether sectoral independence also implies lack of coercion or constraint, disinterest in profit, ethical or legal distribution constraints, remains an open question. A philanthropic sector has been construed as consisting or individuals and organizations devoted to private action for the public good. (Indiana Center, 1990) As an organization, Independent Sector has produced an interesting and useful typology of "the independent sector". The widespread reintroduction of philanthropy as an umbrella term breathes new life into a word with an ancient and honorable heritage in both English and its original Greek. (NTEE, 1988) Yet, each term has attracted minimal conceptual justification, definition or classification to date. Such issues as whether a non-distribution constraints or uncoerced participation are essential characteristics of private action for the public good have not been closely examined.

As if the present welter of sector terms wasn't enough, we might even go so far as to suggest at least three more candidates. In seeking suitable sector terms, we might suggest that an eleemosynary sector is one based on donations. Donative behavior is at least as characteristic of segments of "the sector" as other forms of volunteer labor. Eleemosynary behavior is not uniquely characteristic of the JudeoChristian tradition, as sometimes suggested. Each of the world's major religious systems is built at least partially on an eleemosynary base. Distinctive eleemosynary institutions (kanjin) are evident in Japanese Buddhism as early as the 8th century. (Goodwin, 1987; Lohmann and Bracken, 1991) Similar eleemosynary behavior has been a characteristic of the Islamic charitable tradition of zakat which is one of the five pillars of Islam, and the distinctive Islamic foundations, or Islamic foundations, or waqfs. (Hourami, 1991) Even so, the term, while it in a good bit of state and local legal terminology in the U.S., is probably little more than an anachronism. However, if we conclude that donation is the central characteristic of "the sector", then it must be an eleemosynary sector! Even so, the connections between donative behavior, non-distribution constraints, uncoerced participation, and independent action for the public good have yet to be clearly spelled out in theory.

There is also a large and growing body of psychological literature dealing with altruism, disaster responses, learning of unselfish behavior and related topics in which the concept of prosocial behavior figures centrally. (See Brief and Motowidlo, 1986, for example) From this vantage point, we might speak of the prosocial sector. Prosocial, in this sense, seems to express at an individual level much the same intent as philanthropic at the institutional level. 
Likewise, the growing international dimensions of nonprofit and voluntary action research may eventually bump into the anthropological term for primitive forms of association, or sodalities, , leading perhaps to the suggestion of an international sodality sector. (Hill, 1970, 42-45; Smith and Freedman, 1972, 16-17) The sodality concept seems to embrace many of the implications of distribution, participation and shared purpose without the particular institutional lens of a single culture.

This cursory review of sector terms reveals a consistent pattern behind various attempts to label "the" sector. In each case, an adjective highlighting a single characteristic is used to modify the term "sector", with the implication that this modifier (and the characteristic it signifies) represents the central or critical characteristic of a sector. The logically prior idea that a sector which requires such a label actually exists appears to be taken for granted. In conventional usage, a sector may be a category, division, genre or section of some larger unit. In this case, the larger something of which the sector is a part may be, variously an economy, polity, society or culture, depending upon which disciplines are sectoring.

For interdisciplinary purposes, it seems useful to propose that any meaningful sector of this type must simultaneously be construed as an economic, social, political and cultural unit. The notion of the sector as a unit of analysis defined by a single characteristic (distribution constraints, uncoerced participation, independence, donations, or private action for public good) fit easily within settled disciplinary perspectives, and consequently, treatment of the entire issue of an appropriate term as an unexamined theoretical primitive proved non-controversial.

In the interdisciplinary context of nonprofit and voluntary studies, however, no discipline should blithely take their own primitive terms too much for granted. In this case, a host of questions, including whether that larger unit is an economy, polity, community, society, nation, class or some overarching combination "social system" is also at issue. We need not immediately choose up disciplinary teams and have at one another in a Hobbesian war of each against all.

The immediate question is whether there are any unifying themes or constructs which tie together these modifiers and what they signify in some larger synthesis. Would an impartial observer conclude that contemporary nonprofit, voluntary action and philanthropy studies are addressing one or nine or more distinct sets of phenomena? Is this one science or of many? In response to several reviewers of drafts of this article, it should be said that the multiple paradigm solution cannot and should not be quickly or easily dismissed. It may well be that we are dealing with different sets of unrelated phenomena. On the other hand, it is not necessary to blithely assume that every nuance of terminology or usage is indicative of a separate theoretical universe of discourse. The possibility of a single, common universe of theoretical discourse can be explored here without any necessity of completely dismissing a multiple paradigm solution. 
The theoretical problem presented by the sector talk of the past decade assumes the possibility of one paradigm, however vague or distant perception or understanding of it may be at the moment. There seems to be no good reason to reject that premise at present. Indeed, even the changes in names of the society from AVAS to ARNOVA and the journal from JVAR to NVSQ would appear to indicate increasing interest in the possibility of a single paradigm. The recent creation of an international organization for the study of nonprofit organizations, voluntary associations and philanthropy is perhaps the most inclusive synthesis to date.

\section{Further Synthesis: Commons and Common Goods}

Yet, this remains synthesis by listing: Where ever the list stops, the question of the defining characteristics of the voluntary-independent-private-nongovernmentnon-profit-not-for-profit-elemosynary-philanthropic-charitable-third-fourth-fifthprosocial-sodality sector remains. The effort here is to move beyond labeling and suggest that the concept of the commons, suitably defined, together with the closely associated concept of common goods offer central unifying concepts with multidisciplinary implications of the type which are needed. To begin with, "the commons" is an appropriate and parsimonious label for what we would all grow weary of calling the V-I-P-N-NP-NFP-E-P-C-T-F-F-P-S sector. Yet, as set forth below, the concept embraces key aspects of each of the single-label terms discussed above. The concept of a commons also offers a suitable basis for both linking and distinguishing such difficult-to-reconcilable concepts as nonprofit organization, volunteerism, charity, philanthropy and altruism. The commons is a genuinely interdisciplinary concept with a pedigree reaching back to ancient Greece along with frequent enough currency of use to escape sounding archaic. It may also prove suitable for linking the divergent scholarly interests of sociologists, political scientists, economists, social workers, philosophers, historians and other researchers and scholars working in this area with those of practitioners interested in the area.

\section{Commons Defined}

The concept of the commons has explicit historic Greek, English and American connotations. It can readily be traced to Aristotle who said that " $(\mathrm{t})$ he good in the sphere of politics is justice; and justice consists in what tends to promote the common interest." (Barker, 1968) Centuries later, St. Augustine also wrote of common goods. (Udoidem, 1988) A large cluster of core concepts and practices linking participation in associations, philanthropic donation, common purpose, and shared resources are traceable to the beliefs and practices of the Athenian Greeks of the ancient world as filtered through the classicism of the Renaissance and Age of Reason. 
The main characteristics of a plausible modern concept of commons are encompassed by Aristotle's concept of koinonia politiké. (usually translated as civil society). According to the ancient historian M.I. Finlay (1974), koinonia involves five related dimensions: 1)Free and uncoerced participation; 2) Common (or shared) purpose, whether major or minor, long term or short. 3)Common holdings (Such as fund of jointly held resources or a collection of precious objects or a repertory of shared actions); 4)Participation involving philia (a sense of mutuality; often inadequately translated as "friendship"); and 5) Social relations characterized by dikiaon (fairness or justice). Collectively, these five dimensions summarize in a single concept (denoted as "the commons") what appear to be the central characteristics most frequently attributed to "the sector."

The English house of commons, where the accent is more upon discussion and debate and political theater than American-style production of legislative outputs is also an important point of reference here. (Ryle and Peters, 1988) So also is English common law, grown up out of precedent and practice rather than deduced from transcendent principle. Finally, the village commons by turns pasture, recreation area, green space, public forum and assembly point for voluntary militias is an equally important reference point.

The American connotations of the commons are mostly associated with the experience of a democratic, pluralistic civil society and federal state which Tocqueville first observed, and with an almost unimaginable variety of groups and communities devoted to peaceful pursuit of their own ends without external authority, control or interference. The scale of the commons in American life is extensive. Even the most cautious observers note upwards of a million nonprofit organizations in the U.S. today. (Weisbrod, 1988) If one incorporates "the informal sector" toward which voluntary association concepts point, the number of organized commons would undoubtedly increase several fold, even as the significance of an exact count declines.

A major consequence of this five-part definition of the commons is to relocate the vital center as well as the boundaries between the market, state and the world of nonprofit, voluntary and philanthropic concerns. The sector of the non-distribution constraint on resources is also interpreted by the ideal type of the commons as the common sector of participation, joint purposes, mutuality, and fairness. To the extent that nonprofits display coercive or surplus-maximizing behavior, they can thus be interpreted as theoretically marginal -- at the boundaries between state or market respectively. The existence of coercive or maximizing behavior in the contemporary commons is not at issue. Its defining character is. No one should doubt that "free riding", for example, exists. But it should be equally clear that free riding does not define nonprofit, voluntary or philanthropic behavior, but helps to locate the boundaries between self-interested, profit-oriented market behavior and common behavior. (See Sugden, 1984)

\section{What Public Goods?}


If the commons is seen as a sector characterized by participation, shared purposes and resources, mutuality and concern for fairness, what implications does this have for interpreting the outcomes or results of common effort? The term "common" is sometimes used in political theory as a synonym for "public" (as in the reference to Aristotle above). As such, common good, public good, public interest and general will are often used to represent closely related ideas. (See recent works by Raskin, 1986; and Daly and Cobb, 1989) In this context, it is possible to set forth a conception of common good which is consistent with the major conclusions of this literature and yet useful for distinguishing the "products", outcomes or results of common action from those of the marketplace or state.

The concept of goods as a way of focusing on the positive or desirable qualities of an object and on the outputs of particular social, economic or political processes has definite interdisciplinary possibilities. These possibilities are explored, for example, in John Rawls' discussion of "the full theory of goods" in his theory of justice.

(Rawls, 1971, 433-439) The key question, in the case of commons characterized by participation, shared purposes and resources, mutuality and fairness, involves what we might say about the nature of the goods expected or resulting from common action?

Perhaps the single most common resolution of the goods problem in contemporary nonprofit, voluntary and philanthropic studies is the suggestion that the sector is characterized by private production of public goods. (Austin, 1983; Sugden, 1984; Weisbrod, 1988; ) Yet, the public goods formulation is, at best, only a partial solution. The concept of public good has a precise and exact definition to which many forms of nonprofit, voluntary and philanthropic action simply do not adhere. Public goods are, by definition, universal and indivisible. In no meaningful sense can it be suggested, for example, that associations of bird watchers, antique car collectors, charismatic cultists or committees of volunteers counting whales are engaged in the private production of public goods. Yet these are equally as characteristic of the sector as hospitals, nursing homes and government-subsidized social service "firms".

The shared purposes and outcomes of all types of commons except one fail to correspond to any precise definition of public goods. Common purposes need not be universally perceived as good nor indivisible in their impacts. When common purposes are perceived as universally good and indivisible in their impact, the theoretical result is virtually the convergence of the commons and the state in a kind of "general will" ala Rousseau. Short of this, one can look to neither political nor economic theory to justify the private production of public goods idea. Udoidem (1988) suggests a way out of that box by contrasting the common (or public) good from $a$ common good; the former being a unitary concept characterized by universality and indivisibility like public goods and the public interest. It is the latter notion of a common good which is of greatest immediate interest here. 


\section{Common Goods}

By loading all of the above connotations of the noun commons above into an adjective-modifier, we can suggest the principal characteristics of the principal outcomes of nonprofit, voluntary and philanthropic effort. Common goods are, in other words, desirable or preferred outcomes which are uncoerced, associated with shared purposes and pooled resources; goods which also engender a sense of mutuality (we often say community) and fairness (or justice).

Each sector, in other words, is theoretically associated with a distinctive type of good: Markets produce private goods, states public good and commons engender common goods. (The distinction of these ideal types also allows us to consider the marginal cases in which, for example, markets produce common goods and commons produce private or public goods). In contrast with both private and public goods, common goods involve purposes, goals, objectives, or outcomes shared by a particular group, interest, faction or party, whether in agreement or opposition to other ("outside") interests or simply indifferent to them. Thus, common goods may have limited appeal without being universally held up as desirable. Within a particular reference group, they may share with public goods the qualities of indivisibility and universality. Yet outside that reference group, any common good may be a matter of indifference or even be considered a "bad".

Many of the best examples of common goods involve religious ritual and beliefs. Attending mass is central to the meaning of being a Roman Catholic. It is, in that sense, universal within the Catholic commons. The mass is also indivisible. One does not receive "partial credit" for attending part of a mass. Like ceremonies and rituals of all types, the mass is, for its adherents, an indivisible and universal good. Yet, to non-Catholics the mass is not a good. It may be a matter of indifference or, as in the case of several different Protestant reform movements, a source of antagonism and outright opposition (a "bad" rather than a good). It is, in other words, a clear example of a common good. The same may be said for Christian baptism and communion; Jewish Passover; Islamic observance of Ramadan or the pilgrimage to Mecca and other principal religious ceremonies, rituals and observances. Indivisibility arises out of the inherent unity of the observance, but the observance as a good is understood, accepted and valued only within a recognized community of believers whose recognition of the good and recognition of one another are intimately connected.

A distinction of multiple common goods and the common (or public) good is useful for reconciling external, or community, conditions of plurality with the internal, or organizational, striving for solidarity which is one of the essential characteristics of commons. Treating the purposes and outcomes of commons as common goods, therefore, can do much to resolve the paradoxical, confusing and inconsistent applications of the concept of public goods to the analysis of nonprofit and voluntary action 


\section{Conclusion}

The commons as an environment of uncoerced participation, shared purposes, shared resources, mutuality and fairness, and the closely related concept of common goods to characterize the purposes and the outputs of common effort appear to be a promising base upon which to build an interdisciplinary approach to the whole field of nonprofit and voluntary action studies.

The five theoretical dimensions of the commons, for example, offer a lattice which gives meaning to the non-distribution constraint and transform it beyond an empty legal formalism into a potentially powerful normative idea. These characteristics are also many, if not most, of the characteristics frequently ascribed to voluntary action. Emphasizing the "thirdness" of the nonprofit, voluntary and philanthropic sector has proven to be a heuristic which has made it possible to translate a jumble of competing and overlapping institutional perspectives into the unity whose characteristics the concept of the commons describe. Likewise, the negations such as "nonprofit" and "nongovernmental" serve to locate the third sector outside market and state, still without identifying any of its salient characteristics. The independence that comes from shared purpose and resources is surely one of those characteristics, but the concept of the commons allows us to remember that there are others as well. It is a small linguistic step from construing philanthropy as "private action for the public good" to "private action for common goods", but such a move has the potential of theoretically restructuring some of the most controversial questions in the field. Eleemosynary or donative behavior is an obviously important element in a sector in which sharing and mutuality are central characteristics. The idea of prosocial behavior speaks very clearly to all manner of individual participation and sharing in pursuit of common goods.

Perhaps most important of all in the current era of heightened international interest in nonprofit organizations, voluntary action and philanthropy, the sodality concept serves as a constant remainder that most studies in this field have concentrated upon late 20th century American cases and examples. Clearly, many of the basic concepts of the field extend beyond the U.S. context. Yet, no one can be completely clear on exactly how far, and what transformations will occur as a result. Commons and common goods may describe cultural universals, nearuniversals, institutions unique to an emerging world culture, or they may relate only more narrowly to the West, to Anglo-America or to some more limited subset of nations, societies or cultures.

The concepts of commons and common goods also bring together many different disciplinary perspectives. Free labor which is also committed to shared purposes and resources, mutuality and fairness in the pursuit of common goods should be the central concern of nonprofit economics. Voluntary action in pursuit of mutual objectives with shared resources not only produces the solidarity based on mutuality and fairness; it also yields a unique solution to the Hobbesian problem of order which has been of central concern to sociologists. Psychologists exploring 
prosocial behavior of children, students and others, and anthropologists studying mutual aid and the primitive associations of sodality in many cultures have much to contribute to broadening and deepening our understandings of commons and common goods. At the same time, there is embedded within the concepts of commons and common goods the potential for understanding the legal, administrative and organizational problems in the contemporary practice worlds of foundations, public agencies, nonprofit organizations, fund raising, volunteering, and co-production.

Together, the concepts of commons and common goods offer the conceptual anchor of a genuinely syncretic synthesis of the many different disciplinary paradigms which define the present interests of those working on nonprofit and voluntary studies. 


\section{References}

Austin, D. M. (1983) The Political Economy of Human Services. Policy and Politics. 11 3. 343-359.

Barker, E. (1968) The Politics of Aristotle. London: Oxford University Press.

Bauer, R. (1990) Voluntary Welfare Associations in Germany and The United States: Theses on the Historical Development of Intermediary Systems. Voluntas, 1. 1, 97-111.

Bernstein, R. (1983) Beyond Objectivism and Relativism: Science, Hermeneutics and Praxis. Philadelphia: University of Pennsylvania Press.

Brief, A. P. and Motowidlo, S. J. (1986) Prosocial organizational behaviors. Academy of Management Review, 11 4, 710-725.

Cornuelle, R. C. (1965). Reclaiming the American dream. New York: Random House.

Daly, H. E. and Cobb, J. B. (1989) For the Common Good: Redirecting the Economy Toward Community, the Environment and a Sustainable Future. Boston MA: Beacon Press.

Douglas, J. (1987) Political Theories of Nonprofit Organization. In W.W. Powell (ed.), The Nonprofit Sector: A Research Handbook. New Haven, CT: Yale University Press.

Finlay, M. I. (1974) The Ancient Economy. Berkeley CA: University of California Press.

Ford Foundation. (1989) The Common Good: Social Welfare and the American Future Policy Recommendations of the Executive Panel. Ford Foundation. New York.

Goodwin, J. R. (1987) Alms for Kasagi Temple. The Journal of Asian Studies, 46. 4., 827-840.

Hansmann, H. (1987) Economic Theories of Nonprofit Organization. In Powell, W.W. (ed.) The Nonprofit Sector: A Research Handbook. New. Haven CT, Yale University Press, 27-42.

Hill, J. N. (1970) Prehistoric Social Organization in the American Southwest: Theory and Method. In Longacre, W. A. Reconstructing Prehistoric Pueblo Societies. Albuquerque: University of New Mexico Press. 11-58.

Hourani, A. (1991) A History of the Arab Peoples. Cambridge MA: Harvard University Press.

Independent Sector. (1987) National Taxonomy of Exempt Entities [NTEE] : A System for Classifying Nonbusiness, Tax-exempt Organizations in the U.S. 
with a Focus on IRS Section 501 (c) (3) Philanthropic Organizations. Washington DC: Independent Sector.

Jordan, B. (1989) The Common Good: Citizenship, Morality, and Self-Interest. New York: Basil Blackwell.

Kramer, R. (1981) Voluntary Agencies in the Welfare State. Berkeley CA: University of California Press.

Lohmann, R. (1989) And Lettuce Is Nonanimal: Nonprofit and Voluntary Sector Quarterly. 18. 4. 367-383.

Lohmann, R. and M. Bracken. (1991). The Buddhist Commons in Japan and Asia. Paper presented at the annual conference of the Association for Research on Nonprofit Organizations and Voluntary Action. Chicago, Illinois.

O'Neill, M. (1989) The Third America: The Emergence of the Nonprofit Sector in the United States. San Francisco: Jossey Bass.

Pifer, A. (1984) Philanthropy in an Age of Transition: The Essays of Alan Pifer. New York: The Foundation Center.

Raskin, M. (1986) The Common Good: Its Politics, Policies and Philosophy. New York: Routledge \& Kegan Paul.

Rawls, J. The Theory of Justice. Cambridge MA: Harvard University Press. 1971.

Ryle, M. and P. G. Richards. (1988) The Commons Under Scrutiny. London: Routledge.

Salamon, L. (1987). Partners In Public Service: The Scope and Theory of Government-Nonprofit Relations. In W.W. Powell (ed.), The Nonprofit Sector: A Research Handbook. New Haven, CT: Yale University Press.

Sherover, C. M. (1989). Time, Freedom and the Common Good. New York: State University of New York Press.

Smith, A. (1981) The Wealth of Nations. New York: Penguin Books.

Smith, C., and Freedman, A. (1972) Voluntary Associations: Perspectives on the Literature. Cambridge MA: Harvard University Press.

Smith, D. H. (1991) Four Sectors or Five? Retaining the Member-Benefit Sector. Nonprofit and Voluntary Sector Quarterly. 20 2. 137-151.

Smith, D. H. (1974) Voluntary Action Research: 1974. Lexington MA: D.C. Heath \& Co.

Sugden, R. (1984) Reciprocity: The Supply of Public Goods Through Voluntary Contributions. The Economic Journal. 94. 772-787.

Udoidem, S. I. (1988) Authority and the Common Good in Social and Political Philosophy. Lanham MD. University Press of America. 
Van Til, J. (1988) Mapping the Third Sector: Voluntarism in a Changing Social Economy. New York: Foundation Center.

Weisbrod, B. (1988) The Nonprofit Economy. Cambridge MA: Harvard University Press. 